\title{
ARTIGO
}

\section{POR UMA PEDAGOGIA CRIADORA E IMAGINATIVA: retratos de uma prática docente transformadora}

\author{
FOR A CREATIVE AND IMAGINATIVE PEDAGOGY: portraits of a transforming teaching \\ practice
}

\author{
Eliane Pawlowski Oliveira Araujo \\ Claudio Paixão Anastácio de Paula
}

${ }^{1}$ Pós-doutoranda em Ciência da Informação pela Universidade Federal de Minas Gerais (UFMG).

E-mail: elianepaw@yahoo.com.br

2 Doutor em Psicologia pela Universidade de São Paulo (USP).

E-mail: claudiopap@hotmail.com

\section{ACESSO ABERTO}

Copyright:Esta obra está licenciada com uma Licença Creative Commons Atribuição 4.0 Internacional. (cc) B BY

Conflito de interesses: Os autores declaram que não há conflito de interesses.

Financiamento: Não há.

\section{Declaração de Disponibilidade dos dados:} Não se aplica.

Recebido em: 24/04/2019.

Revisado em: 02/05/2019.

Aceito em: 09/05/2019.

\section{Como citar este artigo:}

ARAUJO, Eliane Pawlowski Oliveira; ANASTÁCIO DE PAULA, Claudio Paixão. Por uma pedagogia criadora e imaginativa: retratos de uma prática docente transformadora. Informação em Pauta, Fortaleza, v. 4, n. especial, p. 62-81, maio 2019. DOI: https://doi.org/10.32810/25253468.ip.v4iEspecial.2019.41103.62-82

\section{RESUMO}

A Ciência da Informação, pela inserção de pesquisadores de várias áreas interessados no estudo da informação enquanto objeto científico, acaba tornando-se, à parte qualquer polêmica a respeito, um campo interdisciplinar. Sua práxis pode se fortalecer enormemente se as investigações realizadas na área repercutirem no ensino numa perspectiva afinada com a noção segundo a qual o professor deve, obrigatoriamente, ser um pesquisador. Essa ideia, esboçada por Paulo Freire, parte do pressuposto de não ser possível o real ensino sem pesquisa, e vice-versa. 0 presente artigo procura destacar essa indissociação por meio da análise dos relatos de experiências vivenciados por vários alunos e colegas que cruzaram a trajetória da pesquisadora Adriana Bogliolo Sirihal Duarte, docente da Escola de Ciência da Informação da Universidade Federal de Minas Gerais. Mais ainda, pretende apontar o percurso dessa professora, formada inicialmente em Ciência da Computação, que foi entremeado não só de relevante contribuição para a área, mas de uma prática educativa exercida com afetividade, alegria, capacidade científica e domínio técnico a serviço da mudança, características que Freire atribui ao professor ideal.

Palavras-chave: Adriana Bogliolo Sirihal Duarte. Fazer pedagógico. Espírito científico. Imaginação criadora.

\section{ABSTRACT}

Information Science, through the insertion of researchers from various areas interested in the study of information as a scientific object, ends up becoming, apart from any controversy about it, an interdisciplinary field. Its praxis can be greatly strengthened if the investigations carried 
out in the area have repercussions on teaching in a perspective that is in tune with the notion that the teacher must, necessarily, be a researcher. This article seeks to highlight this association by analyzing the experiences of several students and colleagues who crossed paths with the researcher Adriana Bogliolo Sirihal Duarte, a professor at the School of Information Science of the Federal University of Minas Gerais. Moreover, it intends to point out the path of this teacher, initially formed in Computer Science, which was punctuated not only by relevant contribution to the area, but by an educational practice performed with affection, joy, scientific ability, and technical mastery in the service of change, characteristics that Freire attributes to the ideal teacher.

Keywords: Adriana Bogliolo Sirihal Duarte. Pedagogical doing. Scientific spirit. Creative imagination.

\section{IINTRODUÇÃO}

Esse texto poderia começar com um "Era uma vez uma professora..." porque é desta forma que histórias que fazem a diferença se eternizam. Exemplos, lembranças, ensinamentos e um ombro amigo se entrelaçam com competência, paixão pela docência e comprometimento e tornam únicos certos professores que passam pela vida de muitas pessoas e permanecem vivos em suas memórias. Essas características, contudo, nem sempre são destacadas no dia-a-dia nas instituições de ensino e permanecem como marcas apenas para aqueles envolvidos nas relações de afetividade que são construídas no contexto escolar.

Considerando, entretanto, que o ambiente acadêmico, principalmente o universitário, tem se configurado nos últimos anos como um cenário sufocado pela exigência de publicações, cobrança por internacionalização e sobrecarga acadêmicocientífica, culminando muitas vezes em questões que envolvem a saúde mental de professores e alunos, destacar pontos que não são mensuráveis a partir de uma análise do currículo Lattes se torna cada vez mais urgente.

Neste sentido, o presente artigo se propõe a apresentar uma das vertentes de atuação da professora Adriana Bogliolo Sirihal Duarte, docente da Escola de Ciência da Informação da Universidade Federal de Minas Gerais, que demonstra que a docência não se faz apenas em 50 minutos de uma hora/aula. Estabelecendo um diálogo da trajetória da docente com as proposições do educador Paulo Freire, pretende-se destacar as contribuições da referida professora na construção de uma Ciência da Informação pautada no desenvolvimento de competências individuais e institucionais, na indissociação ensino-pesquisa-extensão, na visão crítica da área, no desenvolvimento de 
perspectivas inovadoras de investigação e na afetividade como o motor propulsor dessa engrenagem.

\section{UM BREVE CURRÍCULO}

A professora Adriana Bogliolo Sirihal Duarte (Figura 1) graduou-se em Ciência da Computação no ano de 1992, tornou-se Mestre em Ciência da Computação, em 1995, com o trabalho sobre "Configuração de Redes de Distribuição em Sistemas de Telecomunicação" e Doutora em Ciência da Informação, em 2005, com a tese sobre "Informação, comunicação e sociabilidade via Internet: um estudo das interações no ciberespaço entre membros do Movimento Escoteiro". Todos os títulos foram obtidos na Universidade Federal de Minas Gerais (UFMG), instituição de ensino na qual a docente ingressou como Professora, no ano de 2006, para atuar junto ao Departamento de Teoria e Gestão da Informação da Escola de Ciência da Informação.

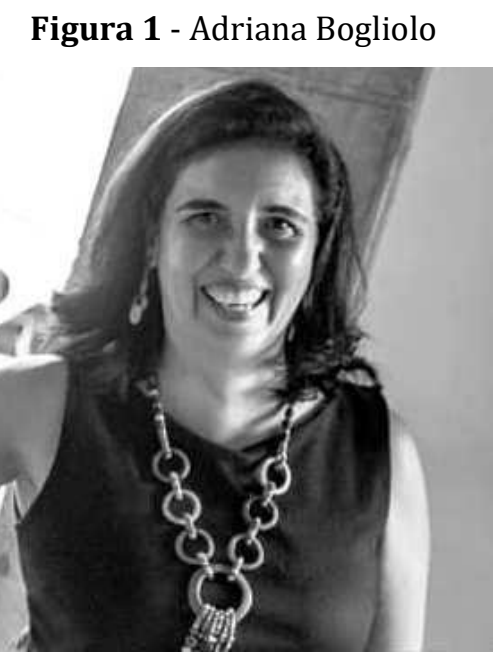

Fonte: Facebook da docente

Na esfera administrativa, Adriana coordenou o Centro de Extensão, foi chefe de Departamento por dois mandatos e Vice-Diretora da Escola de Ciência da Informação. No âmbito de pesquisa seus interesses perpassaram os temas Usuários da informação, Aspectos sociais e culturais da informação, Tecnologias e inclusão digital e Biblioteca escolar. Em função desses interesses, liderou o Grupo de Estudos em Práticas 
Informacionais e Cultura (Epic) e integrou o Grupo de Estudos em Biblioteca Escolar (Gebe).

Considerando a última atualização do currículo Lattes da docente, em janeiro de 2018, é possível verificar sua produção acadêmica: em linhas gerais, foram 36 artigos publicados em periódicos, um livro publicado sobre o projeto de extensão coordenado por ela, sete capítulos de livros, 37 trabalhos completos publicados em eventos e quatro resumos. Adriana orientou 13 dissertações de mestrado e duas teses de doutorado, além de 18 trabalhos de conclusão de curso de graduação, oito monografias de especialização e 14 bolsistas em projetos de iniciação científica. No período de 2016 a 2017, a professora realizou estágio pós-doutoral na Florida State University (FSU), nos Estados Unidos, sobre temática relacionada à Biblioteca Escolar.

\section{DA PEDAGOGIA CRIADORA}

Os quantitativos acima demonstram uma produção que servem de parâmetro para os relatórios de desempenho acadêmico. Porém, não são suficientes para traduzir o desempenho de um professor em outros aspectos que conformam a prática docente. Para essa análise, considera-se que a referência deve se pautar, não no ramo da produtividade, mas em parâmetros que se situam no campo da Educação.

Paulo Freire, educador brasileiro de reconhecimento internacional, é um dos autores que bem traduzem essa dimensão da prática docente. 0 autor considera que o cotidiano do professor, que acontece tanto na sala de aula quanto fora dela, deve se basear em uma pedagogia fundamentada na ética e no respeito à dignidade, o que implica uma convivência amorosa com os alunos, dimensões que não são mensuráveis em relatórios estatísticos.

Edina Oliveira, ao prefaciar a obra de Freire (1996, p. 10), destaca as ideias deste autor de que uma prática pedagógica criadora, assim como os demais saberes, demanda do educador um exercício permanente:

A competência técnico científica e o rigor de que o professor não deve abrir mão no desenvolvimento do seu trabalho, não são incompatíveis com a amorosidade necessária às relações educativas. Essa postura ajuda a construir o ambiente favorável à produção do conhecimento onde o medo do professor e o mito que se cria em torno da sua pessoa vão sendo desvalados. 
Freire (1996) enxerga a prática docente enquanto dimensão social da formação humana e vê a solidariedade como uma das formas de promover e instaurar a "ética universal do ser humano". O educador considera que a formação é muito mais do que simplesmente treinar o educando no desempenho de destrezas. Para ele, ensinar não é transferir conhecimentos, mas, sim, criar as possibilidades para sua produção ou construção.

Sobre a ética, Freire (1996) a aborda como uma "ética universal do ser humano", ou seja, a ética como marca da natureza do homem enquanto sujeito e algo absolutamente indispensável à convivência humana. Para o autor, a melhor maneira de trazê-la na atuação docente é vivê-la na prática cotidiana e testemunhá-la no dia-a-dia com os educandos. Isso pode ocorrer no modo como os professores lidam com os conteúdos que ensinam e também no modo como citam autores de cuja obra discordam ou concordam. Para ele, o preparo científico do docente deve coincidir com sua retidão ética:

Formação científica, correção ética, respeito aos outros, coerência, capacidade de viver e de aprender com o diferente, não permitir que o mal-estar pessoal ou a antipatia com relação ao outro nos façam acusá-lo do que não fez são obrigações a cujo cumprimento devemos humilde, mas perseverantemente nos dedicar.

É não só interessante, mas profundamente importante que os estudantes percebam as diferenças de compreensão, as posições às vezes antagônicas entre professores na apreciação dos problemas e no equacionamento de soluções. Mas é fundamental que percebam o respeito e a lealdade com que um professor analisa e critica as posturas dos outros. (FREIRE, 1996, p. 16-17)

Ao falar da prática docente tendo como princípio norteador uma pedagogia criadora, Freire (1996) demonstra que a educação pode ser algo diferente do que os modelos tradicionais preconizam e que se caracterizam como uma "educação bancária". Nesta, a prática educativa apresenta uma característica imobilista, transferidora de conteúdos e que se opõe ao entendimento do autor de que em todo homem existe um ímpeto criador, sendo a educação mais autêntica quando desenvolve esse ímpeto ontológico de criar (FREIRE, 2016). 


\section{DA PRÁTICA DOCENTE TRANSFORMADORA}

0 entendimento de Paulo Freire sobre a docência vivenciada por meio de uma "pedagogia da autonomia" pode ser vislumbrado na prática docente de Adriana Bogliolo, o que nos leva a abordar sua atuação como professora e pesquisadora na vertente de uma "ação transformadora". Essa identificação, na qual os princípios conceituais se alinham aos práticos, pode ser vista nas falas dos alunos da referida docente, oriundos do programa de pós-graduação em Ciência da Informação, da graduação em Biblioteconomia, bem como de seus colegas de Universidade.

Verifica-se que as características que Freire (1996) atribui a essa pedagogia, que são apresentadas num "plano conceitual", podem ser visualizadas nas rememorações ${ }^{i}$ que foram feitas pelos alunos da professora Adriana Bogliolo em evento realizado em fevereiro de 2019 na UFMG (Figura 2). Denominado "II Jornada em Práticas Informacionais", o evento foi promovido pelo grupo de pesquisa Estudos em Práticas Informacionais e Cultura (Epic) como forma de homenagear a docente por ocasião do seu falecimento, em dezembro de 2018, e destacar sua relevante contribuição para o fortalecimento da Ciência da Informação.

Figura 2 - II Jornada

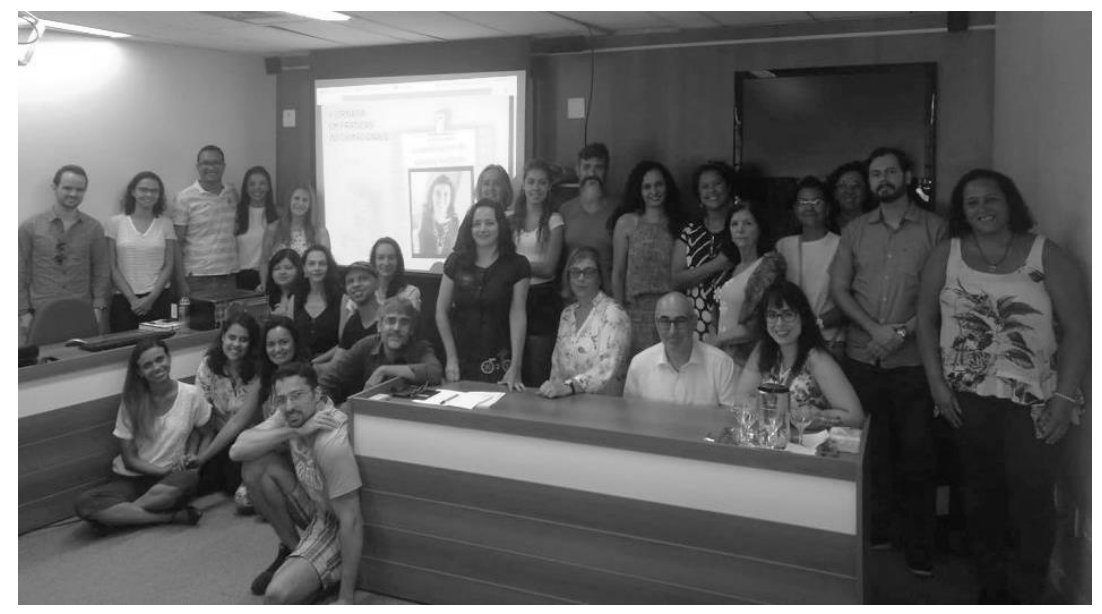

Fonte: Facebook

O evento, entretanto, constituiu-se mais do que um tributo à memória de uma grande professora; foi responsável também por demonstrar que a pedagogia pregada por Paulo Freire não se situa no nível de apenas mais um discurso, mas que se 
personifica no trabalho daqueles que são realmente comprometidos com a educação no sentido de formação integral do indivíduo, como será demonstrado nos paralelos feitos a seguir:

a) Ensinar exige rigorosidade metódica, diz Paulo Freire. Esse argumento se baseia no entendimento do autor da necessidade de uma aprendizagem crítica: "0 educador democrático não pode negar-se o dever de, na sua prática docente, reforçar a capacidade crítica do educando, sua curiosidade, sua insubmissão" (FREIRE, 1996, p. 26).

Essa característica pode ser vislumbrada na atuação de Adriana, que tinha como marca o incentivo ao aprendizado de seus alunos não apenas no que se relacionava a conteúdos teóricos, mas no exercício de sua autonomia. Para Freire (1996, p. 26), a verdadeira aprendizagem pressupõe que os educandos "vão se transformando em reais sujeitos da construção e da reconstrução do saber ensinado, ao lado do educador, igualmente sujeito do processo".

O depoimento de Thaiane, aluna na graduação em Biblioteconomia, demonstra essa faceta da educadora:

o que ela contribuiu para o meu profissional hoje [...] o quão importante ela foi pra mim, porque desde que eu entrei para a biblioteconomia eu nunca gostei de biblioteca escolar [...] e eu falei com ela que queria fazer outra coisa na computação e ela olhava assim pra mim e dizia "bom, se você quer, por que não?" [...] Foi uma experiência sensacional.

Ela, por várias vezes, me deixou lecionar algumas aulas; tipo assim, ela tava lá e dizia "Thaiane, eu sei que você gosta disso, você quer falar?" Sabe, ela não precisava ter feito isso; ela não me jogou lá e disse "como monitora você se vira". Não, ela fazia com carinho porque ela queria me dar oportunidade: [...] "Você pode ir mais além."

No II Ciclo eu participei como apresentadora. No III Ciclo, como organizadora. Foi uma experiência sensacional que eu levo pra vida inteira.

b) Ensinar exige pesquisa, diz Paulo Freire. Esse argumento se baseia no entendimento do autor de que por meio da pesquisa é possível conhecer o que não se conhece e anunciar uma novidade. Essa relação da pesquisa com o ensino, segundo Freire (1996, p. 29), se dá no sentido de que "Ensino porque busco, porque indaguei, porque indago e me indago":

Fomos amadurecendo juntos o quadro de estudos de usuários [...] A contribuição dela muito forte é na parte metodológica, a precisão conceitual. 
Em 2014 nós propusemos a criação do Epic [...] Nossa ideia foi firmar nesse compromisso da consolidação de um grupo de pesquisa. [...] Hoje nós temos um grupo de pesquisa que é composto por cinco professores da ECI, por seis pesquisadores doutores [...] temos um conjunto de doutorandos, de mestrandos, que estão conosco acreditando numa maneira de construir pesquisa. Uma maneira que é inovadora, ela é ousada e ela prima, ela busca, ela é muito sintonizada com uma perspectiva de um referencial teórico com mais complexidade para capturar a complexidade dos fenômenos [...] Existe um reconhecimento do Epic no Brasil. [...] É um grupo de Minas Gerais [...] do qual fazem parte professores da Espanha, do Uruguai, da Argentina e da Colômbia.

Adriana, entre todas as contribuições que ela nos deu, eu destacaria o rigor [...] Ela preparava o terreno para que cada um pudesse ir lá e realizar sua pesquisa. [...] Uma coisa que ela deixou forte para o grupo foi a criação de categorias, a maneira como produzimos categorias de análises dos fenômenos que nós estudamos (Prof. Carlos Alberto).

c) Ensinar exige risco e aceitação do novo. Nesse aspecto destacado por Paulo Freire (1996) é possível perceber uma característica de Adriana que compõe o seu perfil de pesquisador atento aos movimentos do mundo contemporâneo:

Ela estava sempre buscando coisas novas para trazer para os alunos. Essa discussão de práticas, ela e o Casal foram trazendo, e não foi uma coisa colocada pronta: a gente acompanhou, como aluno, como foi se desenvolvendo na Ciência da Informação.

Essa aproximação [aulas e bancas] fez com que a gente se tornasse parceiras, porque meu tema de pesquisa dentro do campo era um tema que trazia coisas novas. Eu procurei estudar a tomada de decisão organizacional vendo os aspectos subjetivos, mas utilizando pra isso uma dimensão simbólica. Então a Adriana acompanhou como eu desenvolvi minha pesquisa e, a partir de ver esse processo, ela passou a me convidar para apresentar aos alunos nas aulas [...] outras opções metodológicas, outras teorias que poderiam ajudar o campo a ser visto de uma forma mais abrangente. Não eram só questionários e entrevistas, mas havia outras formas de pesquisar. (Eliane Pawlowski)

d) Ensinar não é transferir conhecimento, mas criar as possibilidades para a sua própria produção ou a sua construção. Segundo Freire (1996, p. 38), a grande tarefa do educador não é transferir, depositar ou oferecer ao outro, tomado como paciente de seu pensar, a intelegibilidade das coisas, dos fatos e dos conceitos, mas desafiar o educando a produzir sua compreensão do que vem sendo comunicado. Para ele, "Não há intelegibilidade que não seja comunicação e intercomunicação e que não se funde na dialogicidade". Na prática acadêmica de Adriana essa característica pode ser percebida em vários momentos: 
Ela me ensinou a descobrir o potencial que eu tinha dentro de mim. Ela tem o potencial de nos fazer acreditar. [...] A Adriana contribuiu sim para minha formação, me ensinou o que é ser uma profissional bibliotecária e pesquisadora com ética, responsabilidade, com rigor; acreditou em quem eu sou, acreditou que eu sou capaz. (Pamela)

Ela tem uma didática muito boa para te mostrar os caminhos. (Flávia)

Ela tinha ideias boas e ela era uma pessoa muito boa de trabalhar porque ao mesmo tempo em que ela tinha uma acolhida, ela era objetiva. [...] tenho muito a agradecer a ela pela acolhida, pelo trabalho conjunto. (Eliane Rocha)

e) Ensinar exige alegria e esperança. Na prática de Freire, o envolvimento com a prática educativa (sabidamente política, moral, gnosiológica) jamais deixou de ser feito com alegria, o que não significa dizer que ele tenha invariavelmente podido criá-la nos educandos. Mas, estando preocupado com ela, enquanto clima ou atmosfera do espaço pedagógico, Freire nunca deixou de se empenhar em buscar e incentivar esse envolvimento (1996, p. 72).

Percebe-se nessa visão de Freire uma grande semelhança com a ação educativa de Adriana. É possível reconhecer nas duas a mesma relação entre a alegria necessária à atividade educativa e a esperança. Nas palavras de Freire (1996) a esperança de que professor e alunos juntos podem aprender, ensinar, inquietarem-se, produzir e juntos igualmente resistirem aos obstáculos à sua alegria. Em ambas as práticas, de Freire e de Bogliolo, percebe-se a certeza de que, do ponto de vista da natureza humana, a esperança não é algo que a ela se justaponha, a esperança é parte constituinte da natureza humana:

o que eu acho que a gente deve guardar da Adriana é a alegria dela e a firmeza dela de lidar com situações as vezes muito difíceis (Profá Mônica Nassif).

Trabalhar com a Adriana era extremamente bacana. Era uma cumplicidade, era realmente trabalha junto [...] A gente trocava muita ideia. [...] Ela tinha uma disponibilidade de dividir: "olha, eu vi isso lá e isso serve pra gente". (Raquel)

o quanto ela era iluminada, colorida, jovial, generosa, [tinha] essa qualidade do diálogo, do ouvir. [...] postura, alegria, generosidade, seriedade. (Profa Marília)

f) Ensinar exige segurança, competência profissional e generosidade. Paulo Freire (1996) considera que a segurança com que a autoridade docente se move fundamenta-se na sua competência profissional. Contudo, para Freire (1996), a prática democrática do docente não é determinada apenas pela competência 
científica, mas alia-se à generosidade na medida em que não há nada que inferiorize mais a autoridade do que a arrogância e a mesquinhez no comportamento. Esses atributos de Adriana, que aliam competência e generosidade, podem ser percebidos nas seguintes falas:

O que ela tinha de melhor era a generosidade e acreditar nas pessoas. [...] Em nenhum momento ela deixava de acreditar nos alunos que estavam ali com ela. Ela acreditou que eu daria conta [...], fica minha gratidão (Ruleandson)

As primeiras impressões da Adriana foram de acolhimento, de uma pessoa afetiva, de uma pessoa generosa, de uma profissional super competente eu não tenho palavras o quanto a Adriana me inspirava como professora, como mulher, como pessoa. (Pamela)

Se tem uma coisa que é zero na Adriana é arrogância. (Profa Marília)

g) Ensinar exige comprometimento. Para Freire (1996) não é possível exercer a atividade do magistério como se nada ocorresse com o docente. Desta forma ele entende que uma das preocupações centrais deve ser a de procurar a aproximação cada vez maior entre o discurso e a ação, entre o que se parece ser e o que realmente se é de verdade. Ensinar exige, portanto, na visão desse educador, a corporificação das palavras pelo exemplo. Nesta vertente de observação, percebe-se que a preocupação de Adriana na formação de seus alunos e orientandos não era fruto de um discurso teórico, mas era perceptível pelo seu comprometimento com o desempenho destes:

Pra mim a contribuição mais importante da Adriana é a questão da formação do pesquisador. Ela tinha um extremo cuidado, uma extrema dedicação nesse processo de orientação, que não era simplesmente uma orientação, era a formação de um pesquisador.[...] A Adriana não tinha só esse lado de dar um apoio emocional, psicológico, mas desde o início ela ia ensinando mesmo, formando pesquisadores, ensinando cada etapa, passo a passo, os mínimos detalhes de como fazer uma pesquisa bem feita. [...] A gente buscou junto, a gente construiu junto[...] ela estava ali junto comigo e foi o que deu segurança de que a gente está fazendo um trabalho bem feito. E isso tudo ela fazia com empatia, com extrema sensibilidade e integridade. (Tatiane)

Pra mim a Adriana é um exemplo completo de mulher, de pessoa, de profissional. Incentivo e inspiração. Eu relaciono porque eu cresci em um ambiente muito árido na minha família [...] e ela nunca perdeu uma oportunidade de "encher minha bola"[...] ajudou muito a mudar a visão que eu tenho de mim. Ela sempre respeitou a autonomia do meu trabalho [...] eu construí minha narrativa, ela foi só me direcionando com todo carinho, com toda paciência. Ela me ajudou a diferenciar críticas construtivas de destrutivas. (Maria Amorim) 
h) Ensinar exige saber escutar. O educador que escuta, segundo Freire (1996) aprende a difícil lição de transformar o seu discurso em uma fala, não ao aluno, mas com o aluno. Essa atitude implica, segundo ele, apoiar o educando para que ele vença suas dificuldades na compreensão do objeto e para que sua curiosidade, compensada e gratificada pelo êxito da compreensão alcançada, seja mantida e, assim, estimulada a continuar a busca permanente que o processo de conhecer implica. É neste sentido que o autor considera que se impõe "escutar o educando em suas dúvidas, em seus receios, em sua incompetência provisória. E ao escutálo, aprendo a falar com ele" (FREIRE, 1996, p.119).

\begin{abstract}
Comecei a conversar com a Adriana e ela foi muito pronta a me ajudar a trabalhar esse conceito de ação cultural e levar para o carro biblioteca. Nesse primeiro momento eu ainda não tinha nenhuma experiência de pesquisa, não tinha noção nenhuma, não sabia nem o que era escrever um objetivo de pesquisa, no começo da minha graduação, e a Adriana foi totalmente paciente para me explicar todo um processo de pesquisa,como funciona, metodologia, [...] e eu me lembro que ela estava sempre disponível na sala dela para conversar, sempre. (Pamela)
\end{abstract}

i) Para Freire (1996) ensinar exige querer bem aos educandos. Ele propunha que nada haveria que ser dito e nem nada se poderia esperar de um professor que não fosse tomado por outro tipo de saber: o saber de precisar estar aberto ao gosto de querer bem e, às vezes, à coragem de querer bem aos educandos e à própria prática educativa da qual ele participava. Esta abertura ao querer bem não significava que, por ser professor, o mestre deveria se obrigar a querer bem a todos os alunos de maneira igual. Significava, para ele, que a afetividade não deveria assustar, que o professor não deveria ter medo de expressá-la.

Percebe-se na prática preconizada por Freire e a exercida por Adriana a mesma abertura ao querer bem como uma forma de, autenticamente, selar um compromisso com os educandos, numa prática específica do ser humano. Uma forma de, na visão do autor, descartar como falsa a separação radical entre seriedade docente e efetividade. Para ambos não era certo, sobretudo do ponto de vista democrático, dizer que quanto mais severo, mais frio, mais distante e "cinzento" o professor se põe nas suas relações com os alunos, no trato dos objetos cognoscíveis que deveria ensinar, melhor esse professor seria. A afetividade não se acha excluída da cognoscibilidade no "pensar freiriano" e na 
prática de Adriana. No entanto, percebia-se em ambos, o cuidado para que a afetividade não interferisse no cumprimento ético dos seus deveres como professores no exercício de sua autoridade; com o não condicionamento da avaliação do seu trabalho acadêmico ao maior ou menor bem querer que se tenha por ele. Essa dupla preocupação resulta, por outro lado, na necessidade que Bogliolo tinha de, como Freire, reafirmar a necessidade de não se pensar que a prática educativa vivida com afetividade e alegria, prescinda da formação científica séria e da clareza política dos educadores ou educadoras. Para ambos, a prática educativa era um misto de afetividade, alegria, capacidade científica, domínio técnico a serviço da mudança e uma espécie de pharmakon contra o que Freire chamava de permanência do hoje.

Esta característica talvez seja uma das marcas mais fortes de Adriana. Em vários relatos, seja de alunos, orientandos ou de seus colegas de Universidade, é visível o carinho da docente, que é expresso em diferenciadas situações:

\begin{abstract}
Eu entrei em um processo de adoecimento muito grande e ela foi a pessoa que me acolheu. Ela foi a profissional, a professora e a amiga que ligou pra me dizer "tá tudo bem, calma; tudo vai dará certo". Já teve dias de eu chegar na faculdade e eu corria pra sala dela porque eu não conseguia ir mais para nenhum lugar. E eu me lembro que Adriana me recebia, fechava a porta e por horas ela me ouvia, me abraçava e eu posso dizer que muito da conclusão da minha graduação e do meu mestrado tem muito da parceria, do acolhimento e da amizade da Adriana. (Pamela)
\end{abstract}

Ela me acolheu, principalmente no final da pesquisa [...] meu problema de saúde, isso me influenciou muito porque eu achei que não fosse dar conta de terminar a pesquisa. E ela me acolheu, me deu força e disse que eu ia dar conta sim, que eu ia conseguir (Andreza)

Ela não abria apenas a porta do gabinete, mas da casa dela também pra gente. (Janicy)

Os excertos apresentados, referentes às falas das pessoas que conviveram com Adriana, possibilitaram fazer uma associação entre conceito de professor defendido por Paulo Freire (1980) e a trajetória da docente, e demonstraram que não há um sujeito que ensina e um que aprende, mas sim dois sujeitos que pensam em conjunto e que aprendem um com o outro. Acredita-se que essa relação de confiança e cumplicidade é potencializada porque há um diálogo da razão com a emoção que é alimentado por um simbolismo presente na imagem do professor. 
Os símbolos constituem-se como uma "categoria invisível" e, conforme mencionam Chevalier e Geerbrant (1998), representam um microcosmos, um mundo total que permite concentrar, sobre uma realidade de partida, todas as forças evocadas em todos os planos do cosmos e em todos os níveis de consciência. Segundo os autores, o símbolo é um instrumento de compreensão que conduz às mais profundas dimensões e que tem uma capacidade simultânea de introdução, tanto no cerne individual, quanto no social. Nessa dimensão de análise cabe ressaltar a fala de Jung (1977), um dos autores que destacou a existência de aspectos inconscientes na percepção da realidade de que

[...]quando nossos sentidos reagem a fenômenos reais, as sensações visuais e auditivas, tudo isto, de certo modo, é transposto da esfera da realidade para a da mente. Dentro da mente esses fenômenos tornam-se acontecimentos psíquicos cuja natureza extrema nos é desconhecida[...]. Assim, toda experiência contém um número indefinido de fatores desconhecidos, sem considerar o fato de que toda realidade concreta sempre tem alguns aspectos que ignoramos desde que não conhecemos a natureza extrema da matéria em si. (JUNG, 1977, p. 23)

Percebe-se, assim, que as relações entre professor e aluno, compostas por um emaranhado de relações e afetos, são tecidos tendo uma base que pode se situar, não em um nível consciente, mas como cita Araújo (2018) em suas pesquisas, em imagens oriundas de um imaginário coletivo.

\section{ASPECTOS SIMBÓLICOS DA RELAÇÃO PROFESSOR-ALUNO}

Os modelos exemplares que regem psicologicamente as relações humanas e que parecem transcender história e culturas são frequentemente denominados arquétipos (JUNG, 2000, DURAND, 1997). Como uma tendência estruturadora da experiência humana calcada basicamente nas emoções e na forma como simbolizamos as relações entre os seres humanos e o universo (incluindo a relações dos seres humanos uns com os outros), os arquétipos guardam em si polaridades. Mais que isso, os arquétipos guardam possibilidades: podem ser boas, más ou, mais comumente, situarem-se em algum lugar da infinidade de possibilidades situadas entre os extremos "bom-mau" dessa polaridade mais ampla. Podem, inclusive, ser frequentemente o substrato através do qual se constelam representações mentais multiunívocas que reúnem e buscam 
interlocução entre duas ou mais posições antagônicas de difícil conciliação: os símbolos, já mencionados anteriormente (JUNG, 1986).

A prática docente da professora Adriana, em sua estreita relação com as ideias preconizadas por Paulo Freire para uma prática pedagógica plena, parece remeter, simbolicamente, a um dos aspectos essenciais para a transposição da prática da docente de um modelo tradicional alinhado com um dos extremos da polaridade arquetípica professor-aluno, para outro modelo menos conservador mais afinado com as necessidades da contemporaneidade. Uma passagem de um modelo calcado nas oposições Eu-Outro, agente-receptor ou ativo-passivo (BYINGTON, 1996) - onde o professor se identifica somente com o polo daquele que sabe e identifica o aluno com o polo daquele que deve "receber" o conhecimentoe que implica no reforçamento de uma fantasia, bastante comum na sociedade contemporânea, segundo a qual o bom professor deve transferir o seu conhecimento para os seus estudantes e ir, gradualmente, preenchendo-os com seu conhecimento - para uma postura "suficientemente boa" (WINNICOTT, 1953; SAMUELS, 2002; QUEIROZ e PAULA, 2017).

Nessa nova postura, o professor - ciente da impossibilidade da idealizada "transferência de conhecimento", impõe, gradualmente, um desapontamento sistemático ao aluno diante dessas expectativas quase "mágicas" e promove a sua substituição por uma avaliação mais real do processo de ensino-aprendizagem. Nessa avaliação mais realística, o desapontamento inevitável do aluno com as capacidades "transcendentais" de o professor lhe transferir conhecimento acaba abrindo espaço para um novo percurso de aprendizagem que se situa a meio caminho entre a dependência de antes e a autonomia futura. Essa nova postura, ao falar à experiência das pessoas, mostra ao aluno a possibilidade dele crescer ocupando os espaços deixados em aberto pelo seu professor - agora visto não como um repositório de todo o saber, mas como um interagente no processo de construção de conhecimento que tem características particulares. Dentre essas características está o lugar de tutor que ele ocupa (simultaneamente: facilitador, incentivador e avaliador), sua afetividade e, inevitavelmente, a sua falibilidade. Será exatamente essa falibilidade que tornará possível a esse aluno prosperar como uma entidade criativa e não apenas como um mero reprodutor dos modelos que anteriormente lhe foram apresentados. 
As vantagens dessa postura são evidenciadas nos estudos de Queiroz e Paula (2017) e Sá e Paula (2017), onde em duas situações completamente diversas, é demonstrado que a relação docente-discente culmina, muitas vezes, no estabelecimento de uma relação duradoura de colaboração que ultrapassa a dimensão formal e se prolonga pela vida toda através de um profundo vínculo emocional entre eles. Em ambos os casos é sugerido que essa relação de vínculo estabelecida seja responsável por alimentar um substrato imaginário que virá a ser parte constituinte não somente dessa relação, mas das identidades das pessoas nela envolvidas.

Em outras palavras, ainda remetendo a Queiroz e Paula (2017) e Sá e Paula (2017), quando a relação se horizontaliza e o professor se torna próximo, será exatamente por causa da proximidade dessa relação, que ocorrerá o processo de "desidealizá-lo". O aluno passa a reconhecer esse professor como um modelo humanizado e é esse movimento que torna possível uma "passagem do bastão". Nessa passagem o aluno encontraria espaço para crescer psicologicamente, amadurecer a ponto de, no futuro, sentir-se apto e capaz o suficiente para ocupar um lugar semelhante ao assumido pelo seu preceptor e buscar ele próprio, novas formas de contribuir para a sociedade.

Será um desdobramento particular do impacto dessa vinculação simbólicoafetiva pela via do imaginário - não somente com as pessoas, mas com a própria ciência - na prática docente e na pesquisa da professora Adriana que será alvo de reflexão no próximo tópico.

\section{ESPIRITO CIENTÍFICO E IMAGINAÇÃO CRIADORA}

Existiriam inúmeros caminhos para se buscar a relação entre o imaginário e a ciência. Talvez o mais próximo do discurso acadêmico seja o mais singular de todos, o de um professor de ciências: Gaston Bachelard. Contam que, certa vez, Bachelard ouviu um estudante remeter-se ao seu modo de lecionar tanto a ciência quanto a filosofia como oriundas de um "universo pasteurizado". Sobre essa passagem Bachelard, numa espécie de autocrítica, citada por Quilet (1970, p. 21) apud Japiassu (1976, p.86), iria comentar:

Foi como uma iluminação para mim. Era isso: um homem não poderia ser feliz num mundo esterilizado; era-me necessário introduzir nele certos micróbios para restituir-lhe a vida. Corri em direção aos poetas e ingressei na escola da imaginação. 
Pode-se dizer que, ao ser confrontado por seu estudante, o autor viu constelar-se a sua frente o resultado de um longo período de reflexão que, nos dizeres de Barreto (2016), contrabalançou "os efeitos da organização racional-instrumental do mundo" com gênese uma singular teoria da imaginação que pode ser mais bem descrita a partir da noção de imaginação criadora. É a partir de uma breve leitura da interação desse conceito com a noção clássica bachelardiana de formação do espírito científico que se pretende delinear uma última leitura sobre os comentários sobre a vida e a obra da professora Adriana apresentados até aqui.

Sem medo de cometer uma heresia, poder-se-ia, dizer que a passagem feita pela professora Adriana da graduação e do mestrado em Ciência da Computação para a Ciência da Informação em sua vertente mais ligada à cultura tem notas bachelardianas. Como uma espécie de confirmação dessas notas, está o fato de que a entrada da professora em sua escola de eleição tenha se dado através de pesquisas e docência ligadas a disciplinas que poderiam ter seus títulos reunidos sobre um grande guardachuva chamado "Necessidades e usos da informação". É sintomático dos tempos atuais de "hiperespecialização" que esse seja o último bastião em que a Psicologia - disciplina que em última instância é a que mais coloca em relevância a humanidade dos sujeitos informacionais e que foi reconhecida e apontada por diversos teóricos como uma área interdisciplinar à Ciência da Informação - ainda apareça e seja seriamente considerada (sobre essa questão ver Pinheiro, 2002). E é ilustrativo que tenha sido exatamente essa subárea que tenha capturado a atenção da jovem professora em sua transposição seu curso de formação para o curso em que viria a lecionar.

Essa passagem, que foi marcada desde o início pelo apreço da professora pelas humanidades e pelo mundo das artes - e que a conduziu, inclusive, ao estudo das artes cênicas e a atuação no palco (experiências não mencionados em seu Currículo Lattes) parece remeter a uma busca de um caminho, nas humanidades e nas artes que permitisse ir além não somente do tecnicismo que ela enxergava na Ciência da Computação, mas também da tendência, ainda presente em alguns estudos na área da Ciência da Informação, de "repetir as abordagens convencionais em pesquisas de comportamento [...] informacional [...] num viés nomotético." (PAULA, 2012). A professora Adriana sempre foi um agente neguentrópico que se rebelou contra uma 
visão da Ciência da Informação que se preocupa mais com o estabelecimento de leis ou com o estudo de eventos recorrentes do que com a compreensão daqueles que se tornaram o centro maior dos seus interesses: os sujeitos informacionais. Não é de se espantar que o leitor atento encontre na história da professora o mesmo prazer de render-se aos resultados de se deixar permear pela interação com seus estudantes que foi expressa, em tons diferentes, tanto por Paulo Freire como por Gaston Bachelard.

No trabalho acadêmico e na prática pedagógica cheios de inspiração da professora Adriana fica evidente a resultante de uma rica convergência de posturas sobre sua prática acadêmica. A convergência de uma consciência aberta a um sentimento de infinitude e de uma postura que constata que existem significados no fazer científico e pedagógico que estão para além do que as palavras podem transmitir por completo imprimiu uma dinâmica muito mais rica à produção do conhecimento e à formação de pesquisadores sob sua tutela.

Para Bachelard (BARRETO, 2016), a prática efetiva da ciência deve ter prioridade sobre as construções epistemológicas que tentam compreendê-la, mantendo-se ao lado da produção científica e não lhe impondo ou prescrevendo-lhe condições e limites. A solução radical de Bachelard foi apontar o papel dominante que a imaginação tem sobre o conhecimento e o discurso científico. Para o autor havia um "paradoxo das imagens" nas ciências. As imagens seriam o ponto de partida do pensamento científico e necessárias à evolução deste. As imagens, por fazerem parte da própria estrutura da mente humana, de seu funcionamento elementar, gozariam de uma anterioridade psíquica sobre as ideias. Segundo Bachelard, se por um lado, as imagens estariam na origem do conhecimento científico como um elemento deflagrador da sua intenção; por outro, o pesquisador deveria acautelar-se com a intromissão indébita das imagens no discurso científico. Para o autor, a imaginação humana alimenta dois irmãos inimigos: o sonho e a teoria.

Conforme nos demonstra Barreto (2016), ao mesmo tempo em que a imaginação produz imagens poéticas que instigam a descoberta e os voos da imaginação que lançam o humano à indagação dos "comos" e os "porquês" de si mesmo e do universo que o envolve, também produz seduções imaginárias que falseiam as inferências científicas. Pelo fato de poesia e ciência desenvolverem-se segundo vetores opostos, a adesão acrítica às impressões primitivas das adesões simpáticas imaginárias coloca em perigo a objetividade do conhecimento científico. Diante da impossibilidade das antigas 
condições de devaneio serem eliminadas, tornar-se-ia fundamental saber distinguir entre o imaginário simbólico, afetivo e ardente que é fonte de inspiração e beleza poética que podem fazer brotar um tratado científico, de um segundo imaginário que é fonte de extravio e ilusão para o espírito científico. Em outras palavras, distinguir entre o fogo que foi "descoberto em nós antes de ter sido arrancado do céu" (BACHELARD, 1989, p. 38) e o fogo da explicação racionalista segundo a qual os nossos ancestrais préhistóricos descobriram o fogo ao observar que os incêndios nas florestas durante o verão eram resultado da fricção espontânea dos ramos secos movidos pelo vento. Para Bachelard, se esse fenômeno

[...] houvesse sido observado com toda ingenuidade, nunca se teria pensado numa fricção, mas num choque; ninguém descobriria nada que pudesse sugerir um fenômeno lento, preparado, progressivo, como essa fricção que leva à inflamação da madeira. Chegamos, portanto a esta conclusão crítica: nenhuma das práticas alicerçadas na fricção, usadas pelos povos primitivos com o fim de produzir fogo, pode ter sido sugerida por um fenômeno natural (BACHELARD, 1989 , p. 42).

Essa leitura comporta uma dupla chave: a primeira nos alerta para o fato de que certos produtos da imaginação podem se converter em falsidade ao generalizar um princípio e estender a perspectiva científica para além das suas fronteiras legítimas; a segunda nos introduz a noção de que, na impossibilidade da descoberta da fricção como indutora do fogo ser resultado da mera observação, talvez possa ser postulado que a autonomia do imaginário, ao reunir percepções não reconhecidas (por assim dizer, inconscientes), possa resultar numa inspiração para determinação de uma ação objetiva - no caso apresentado, friccionar dois gravetos para, do atrito entre eles, obter calor e, consequentemente, fogo.

Finalizando, após essa rápida digressão, é relevante destacar a afinada abertura da professora Adriana a esses princípios organizadores que não somente dão consistência ao espírito poético, mas também oferecem inspiração, originalidade, autenticidade, coerência e consistência à investigação científica. Ela sempre se esforçou para incentivar a ousadia criativa e a originalidade de seus alunos; paralelamente, ela sempre foi uma crítica atenta das inconsistências lógicas presentes no discurso das ciências e dos obstáculos epistemológicos que uma abordagem rasa do método científico imprimia a muitos dos estudos desenvolvidos na Ciência da Informação. 


\title{
7 CONCLUSÃo
}

Paulo Freire fala do professor ideal, do ensino com autonomia, do espírito crítico e de uma pedagogia criadora. Mas não fala disso como algo utópico ou como uma tarefa a ser exercida por uma pessoa dotada de superpoderes. 0 educador considera nessa análise que o professor é um indivíduo como os outros, "gente, como a gente" e isso é um fator importante:

\begin{abstract}
Gosto de ser gente porque, inacabado, sei que sou um ser condicionado, mas, consciente do inacabamento, sei que posso ir mais além dele. Esta é a diferença profunda entre o ser condicionado e o ser determinado. A diferença entre o inacabado que não se sabe como tal e o inacabado que histórica e socialmente alcançou a possibilidade de saber-se inacabado. Gosto de ser gente porque, como tal, percebo afinal que a construção de minha presença no mundo, que não se faz no isolamento, isenta as influências das forças sociais, que não se compreende fora da tensão entre o que herdo geneticamente e o que herdo social, cultural e historicamente, tem muito a ver comigo mesmo. (FREIRE, 1996, p. 53)
\end{abstract}

Pelo que foi exposto até aqui, é possível reconhecer esse "gosto por ser gente" como uma abertura ao "suficientemente bom" e ao experienciar em profundidade as nuances da vivência simbólica da relação professor-aluno - com todo o impacto dessa relação na formação de futuros pesquisadores e docentes. E neste trajeto em que se desenvolve a docência cabe destacar a fala de Rubem Alves de que o exercício do ensinar, no contexto de que aprendemos também para a vida, é um exercício de imortalidade: "De alguma forma continuamos a viver naqueles cujos olhos aprenderam a ver o mundo pela magia da nossa palavra. O professor, assim, não morre jamais."

Talvez essa seja a melhor forma de alcançar a imortalidade. Adriana continuará viva nas memórias, nas histórias, nos corações e no legado que deixa para todos que conviveram com ela e todos aqueles que, mesmo sem a ter conhecido, se beneficiarão das sementes que ela plantou ao longo de sua trajetória:

Ela certamente cumpriu com nós todos a missão. Ela esteve conosco o tempo todo. Nas relações que nós tivemos com ela acadêmicas, algumas mais pessoais, ela sempre estava ali. (Profa Marília)

Ela mudou a minha vida. (Janicy)

Na verdade, ela foi uma fada madrinha para todos nós. (Thaiane)

Em mim não fica a tristeza, fica a gratidão. (Ruleandson) 
Isso é a Adriana: afetividade, alegria, uma competência muito grande e domínio técnico, visando sempre a mudança. [...] Ela fazia tudo com amor. (Eliane Pawlowski)

A Adriana está presente. Eu acho que ela está presente pra [sic] todos nós por uma diferença. Todo mundo fez uma fala pessoal por essa diferença. Adriana era amiga e amizade se faz com duas pessoas. Amar a gente consegue amar sem ser correspondido; a gente consegue ser apaixonado sem que a pessoa seja apaixonada de volta. Agora não tem jeito de ser amigo sem ter correspondência. (Prof. Claudio)

\section{REFERÊNCIAS}

ARAUJO, Eliane Pawlowski O. A dimensão simbólica como perspectiva heurística: possibilidades do uso do imaginário em investigações sobre o fenômeno infocomunicacional. In: XI Encuentro de la Asociación de la Universidad de Antioquia - XI EDICIC, Medelín. 2018.

BACHELARD, Gaston. A Psicanálise do Fogo. Lisboa: Litoral Edições, 1989.

BARRETO, Marco Heleno. A imaginação criadora na estética de Gaston Bachelard. São Paulo: Edições Loyola, 2016.

\section{BYInGTON, Carlos, A. B. Pedagogia}

simbólica: a construção amorosa do conhecimento do ser. Rio de Janeiro: Record, Rosa dos Tempos, 1996.

CHEVALIER, Jean; CHEERBRANT, Alain. Dicionário de símbolos: mitos, sonhos, costumes, gestos, formas, figuras, cores, números. 12. ed. Rio de Janeiro: José Olympio, 1998.

\section{DURAND, Gilbert. As estruturas} antropológicas do imaginário. São Paulo: Martins Fontes, 1997.

FREIRE, Paulo. Educação e mudança. 37. ed. Rio de Janeiro, Paz e Terra, 2016

FREIRE, Paulo. Pedagogia da autonomia. Rio de Janeiro, Paz e Terra, 1996.
FREIRE, Paulo. Pedagogia do oprimido. 44. ed. Rio de Janeiro, Paz e Terra, 2005.

FREIRE, Paulo. Extensão ou comunicação? Rio de Janeiro: Paz e Terra, 1980.

JAPIASSU, H. Para ler Bachelard, Rio de Janeiro: Francisco Alves, 1976

JUNG, Carl Gustav. 0 arquétipo com referência especial ao conceito de anima. In: Os arquétipos e o inconsciente coletivo (volume IX/I das obras coligidas). Petrópolis: Vozes, 2000.

JUNG, Carl Gustav. Símbolos da transformação (volume $V$ das obras coligidas). Petrópolis: Vozes, 1986. JUNG, Carl Gustav. 0 homem e seus símbolos. Rio de Janeiro: Nova Fronteira, 1977.

PAULA, Claudio Paixão Anastácio. Proposta de metodologia para a investigação do comportamento de busca informacional e do processo de tomada de decisão dos líderes nas organizações: introduzindo uma abordagem clínica na informação. Anais do XIII ENANCIB. Rio de Janeiro, 2012.

PINHEIRO, Lena Vânia R. Ciência da Informação: desdobramentos disciplinares, interdisciplinaridade e transdisciplinaridade. Rio de Janeiro: IBICT/MCT, 2002.

QUEIROZ, Tatiana Pereira.; PAULA, Claudio Paixão Anastácio. A força do imaginário: 
82 | Araújo; Paula| Por uma pedagogia criadora e imaginativa

apego, vínculo e identidade acadêmica como potencializadores da relação com os egressos.

Prisma.com, Especial (Informação e Imaginário), n. 34, 2017, p. 84-104.

QUILET, P. Bachelard, Paris: Seghers, 1970

SÁ, Rosilene Moreira Coelho; PAULA, Claudio Paixão Anastácio. Compartilhamento de conhecimento na orientação acadêmica: a perspectiva de orientadores. Prisma.com,
Especial (Informação e Imaginário), n. 34, 2017, p. 105-126.

SAMUELS, A. A política no divã. São Paulo: Summus, 2002.

WINNICOTT, Donald. Transitional objects and transitional phenomena. International Journal of Psychoanalysis, v. 34, n. 2, p. 8997, 1953. ${ }^{i}$ As citações feitas nesse artigo referentes aos depoimentos dos alunos estão disponíveis na página do EPIC no
Facebook - https://www.facebook.com/epicufmg/-em vídeos postados no dia 25 de fevereiro de 2019. 